
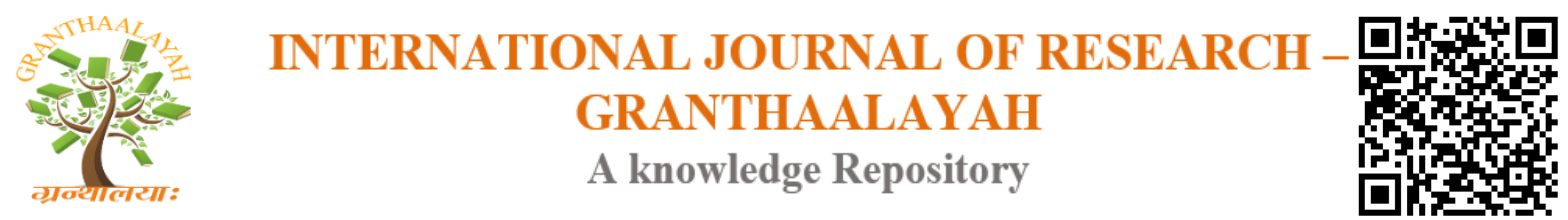

Science

\title{
EFFECT OF GLYCAEMIC CONTROL ON PITUITARY GONADOTROPHINS OF TYPE 2 DIABETIC SUBJECTS IN ENUGU, NIGERIA
}

\author{
Maduka Ignatius $C^{* 1}$, Nnamdi Ngozika $A^{2}$ \\ ${ }^{1}$ Department of Human Biochemistry, Faculty of Basic Medical Science, College of Medicine, \\ Nnamdi Azikiwe University, Awka, Nigeria \\ ${ }^{2}$ Department of Medical Laboratory Science, Faculty of Health Sciences, College of Medicine, \\ Nnamdi Azikiwe University, Awka, Nigeria
}

\begin{abstract}
Glycation is considered to be the main molecular basis of several diabetic complications. Association between chronic hyperglycaemia and the development of long-term diabetic-specific complications have been reported but are yet to be completely understood. In this study, the effect of glycaemic control on pituitary gonadotrophins (FSH and $\mathrm{LH}$ ) was evaluated in male and female diabetics in Enugu, Nigeria. Two hundred and twenty four (240) diabetic patients (92 males and 148 females) within the age range of $31-73$ years, who were receiving treatment, were randomly recruited for the study. One hundred and thirty four (134) age- and sex-matched apparently healthy volunteers (44 males and 90 females) were recruited as the control subjects. The study subjects were grouped into three categories: Male population (40-72 years), Group A Female population ( $<50$ years) and Group B Female population ( $\geq 50$ years). The impact of glycaemic control on various parameters was evaluated by classifying the diabetic patients into 3 subgroups on the basis of their HbA1c levels: Good (HbA1c < 7\%), Fair (HbA1c 7 to 8\%) and (Poor HbA1c > $8 \%$ ) glycaemic status. Fasting blood sugar, HbA1c, FSH and LH were determined for all the subjects. The results obtained revealed that the male diabetics had significantly lower $(p<0.05)$ FSH levels when compared with the control subjects. In the two groups of female diabetic subjects, the FSH levels were significantly lower $(\mathrm{p}<0.05)$ when compared with their respective control subjects. The glycaemic control evaluation and correlation of HbA1c with the gonadotrophins in the male diabetic population show no statistically significant results. However, in the female diabetic population, subjects with poor glycaemic status show significantly increased $(\mathrm{p}<0.001)$ LH levels compared to those with good glycaemic control. In addition, in group B female diabetic population, $\mathrm{HbA1c}$ gave significant positive correlation with both $\mathrm{FSH}(\mathrm{r}=0.261, \mathrm{p}=0.014)$ and $\mathrm{LH}(\mathrm{r}=0.338$, $\mathrm{p}<0.001)$. This suggests that there is a direct relationship between HbA1c and the gonadotrophic hormones. As glycaemic control is compromised, these hormones tend to increase. This study generally reveals increasing trend in the levels of the gonadotrophins across the different glycaemic status. It can be concluded that good glycaemic control of diabetes can exert better influences on pituitary gonadotrophins.
\end{abstract}

Keywords: Glycaemic Control; Pituitary Gonadotrophins; Diabetes Mellitus. 
Cite This Article: Maduka Ignatius C, and Nnamdi Ngozika A. (2018). "EFFECT OF GLYCAEMIC CONTROL ON PITUITARY GONADOTROPHINS OF TYPE 2 DIABETIC SUBJECTS IN ENUGU, NIGERIA." International Journal of Research - Granthaalayah, 6(8), 16-24. https://doi.org/10.29121/granthaalayah.v6.i8.2018.1257.

\section{Introduction}

Hyperglycaemia in diabetics induces non-enzymatic glycation of proteins and lipids. The antidiabetic potential of a possible drug can be considered to be related with inhibition of glycation (Younus and Anwar, 2016). Glycated haemoglobin (HbA1c) has been the most widely used and accepted test for monitoring the glycaemic control in individuals with diabetes (Syed, 2011). HbA1c reflects average plasma glucose over the previous 8 to 12 weeks (Nathan et al., 2007). It provides information about the degree of long-term blood glucose control. According to Arey (2012), several secreted proteins, such as hormones or cytokines, are glycosylated and this has been shown to have influence in determining their activity when bound to receptors. The degree of glycosylation added to these hormones varies depending upon the physiological state. Early glycation and oxidation processes result in the formation of Schiff bases and Amadori products. Further glycation of proteins and lipids causes molecular rearrangements that lead to the generation of advanced glycation end products (AGEs) (Schmidt et al., 1994). AGEs accumulate in tissues and their rate of accumulation is accelerated in diabetes (Popova et al., 2010). This has been linked to various diabetic complications.

Diabetes is a chronic illness that requires continuing medical care and patient's self-management education to prevent acute complication and reduce the risk of long term complication (American Diabetes Association (ADA), 2003). Patients with type 2 diabetes have a combination of insulin resistance and dysfunctional $\beta$ cells, but do not require insulin to sustain life, although insulin eventually will be required to control hyperglycaemia and keep HbA1c below 7\% in $90 \%$ of patients (Harvey and Ferrier, 2011).

Type 2 diabetes has been reported to be associated with hypogonadism due to an impaired secretion of gonadotrophins, including follicle-stimulating hormone $(\mathrm{FSH})$ and luteinizing hormone (LH), by the pituitary gland in the brain (Dandona and Dhindsa, 2011; Chen and Dou, 2014). This may be as a result of insulin resistance itself or the associated underlying mechanism (Ghanim et al., 2001; Dandona et al., 2001).

The high prevalence of hypogonadism in patients with Type $2 \mathrm{DM}$ has been associated with several factors which interfere negatively with the hypothalamus-pituitary-gonadal axis. Among these factors, an important role seems to be played by hyperglycaemia, insulin resistance and by some mediators of inflammation like interleukins and tumor necrosis factor (Dandona and Dhindsa, 2011). According to Chen and Dou (2014), hypogonadism is a risk factor for onset of diabetes, while diabetes is also a risk factor for the development of hypogonadism. The features of sex hormone level in diabetic patients, clinical manifestations, causes and treatments of gonadal disorders complicated with diabetes are unclear.

Hypogonadism in patients with diabetes mellitus (DM) has been associated with both insulin resistance and poor glycaemic control (Onung et al., 2017). This study was thus designed to 
investigate the influence of diabetic control on pituitary gonadotrophins (FSH and LH) in type 2 diabetic subjects.

\section{Materials and Methods}

\subsection{Study Design}

Two hundred and forty (240) diabetic patients (92 males and 148 females) within the age range of 31 - 73 years, who were receiving treatment, were drawn from Enugu State University of Science and Technology (ESUT) Teaching Hospital, Parklane, Enugu. One hundred and thirty four (134) age- and sex-matched apparently healthy volunteers (44 males and 90 females) were recruited as the non-diabetic subjects (control). The selection was carried out via simple random sampling technique. The participants' informed consents and the hospital's ethical clearance were sought and obtained before recruitment. Subjects' general characteristics such as age, sex, smoking status, alcohol consumption, menopausal status for the females and medical history were obtained with the aid of structured questionnaire. Given that some of the biochemical parameters are sex and age dependent, the study subjects were stratified into three categories: Male population ( $\geq 40$ years), Group A Female population ( $<50$ years) and Group B Female population ( $\geq 50$ years). Using Diabetes Control and Complications Trial / National Glycohemoglobin Standardization Program (DCCT/NGSP) classification, the diabetic patients were further categorised into three subgroups on the basis of their glycated haemoglobin (HbA1c) levels: Good Glycaemic Status (HbA1c < 7\%), Fair Glycaemic Status (HbA1c 7 to 8\%) and Poor Glycaemic Status (HbA1c > 8\%).

\subsection{Sample Collection and Biochemical Analysis}

Under aseptic precautions, using a sterile disposable syringe, $6 \mathrm{ml}$ of venous blood was drawn from each subject after overnight fasting. The blood samples for pre-menopausal female subjects were collected at the ovulatory phase of the menstrual cycle.

About $2 \mathrm{ml}$ of the blood was dispensed into fluoride oxalate sample tube and EDTA sample tube for glucose and HbA1c estimations, respectively. The remaining part was dispensed into a plain sample bottle and kept at room temperature to clot, retract and the serum separated into plain tube and stored at $-20^{\circ} \mathrm{C}$ until analysis of pituitary gonadotrophins (FSH \& LH) using Enzyme Linked Immunosorbent Assay (ELISA) technique. Fasting blood sugar was analysed immediately using standard enzymatic spectrophotometric method (Glucose Oxidase method). EDTA whole blood sample for HbA1c estimation was analysed within 7 days of sample collection.

\subsection{Statistical Analysis}

The values were expressed as the mean \pm standard deviation. Means comparisons were assessed by either independent samples t-test or one-way ANOVA, as appropriate. Association of two continuous variables was determined using Pearson's correlation coefficient (r). Statistical software, Statistical Package for Social Sciences (SPSS) Version 23, was used for the statistical analysis. P-value of $\leq 0.05$ was considered significant. 


\section{Results}

In Table 1, the results show that the male diabetic patients had significantly higher mean fasting blood sugar and HbA1c levels $(\mathrm{p}<0.001)$ when compared with the control subjects. In the gonadotrophins, the male diabetics had significantly lower $(\mathrm{p}=0.029)$ FSH level $(8.68 \pm 5.28$ $\mathrm{mIU} / \mathrm{ml})$ when compared with the control subjects $(6.77 \pm 4.07 \mathrm{mIU} / \mathrm{ml})$. There is no significant difference ( $p>0.05)$ in the mean LH levels between the test and control subjects.

As presented in Table 2, It was correspondingly observed that female diabetic patients had significantly higher mean fasting blood sugar and HbA1c levels $(\mathrm{p}<0.001)$ when compared with the control subjects. In both group A ( $<50$ years) and group B ( $\geq 50$ years) female diabetic subjects, the mean levels of FSH $(18.79 \pm 3.73$ and $73.58 \pm 23.25) \mathrm{mIU} / \mathrm{ml}$, were significantly lower $(\mathrm{p}<0.05)$ when compared with their respective control subjects $(20.95 \pm 4.16$ and $82.58 \pm 19.97) \mathrm{mIU} / \mathrm{ml}$. However, there is no significant difference in means between the groups A and B female diabetic subjects and their corresponding control Subjects ( $p>0.05)$.

As shown in Table 3, comparison of the various parameters within the various glycaemic control in the male diabetics. On the other hand, in the female category, the mean levels of FBS, LH, FSH and HBA1c increases significantly $(\mathrm{p}<0.05)$ as the glycaemic control deteriorates. Subjects with poor glycaemic control had significantly higher FBS level when compared to those with good and fair glycaemic control $(\mathrm{p}=0.053$ ). Additionally, it was observed that the patients with poor control had significantly increased LH $(\mathrm{p}<0.001)$ when compared with that of patients with good glycaemic status.

Table 1: Biochemical parameters (Mean $\pm \mathrm{SD}$ ) in male diabetic and male control subjects

\begin{tabular}{|l|l|l|l|}
\hline Parameter & $\begin{array}{l}\text { Diabetic } \\
\text { n=92 }\end{array}$ & $\begin{array}{l}\text { Control } \\
\text { n=44 }\end{array}$ & $\boldsymbol{p}$ value \\
\hline FBS $(\mathrm{mmol} / \mathrm{l})$ & $6.98 \pm 3.07$ & $4.80 \pm 0.33$ & $<0.001^{*}$ \\
\hline $\mathrm{HbA} 1 \mathrm{c}(\%)$ & $7.75 \pm 1.84$ & $4.94 \pm 0.69$ & $<0.001^{*}$ \\
\hline FSH $(\mathrm{mIU} / \mathrm{ml})$ & $8.68 \pm 5.28$ & $10.91 \pm 5.96$ & $0.029^{*}$ \\
\hline $\mathrm{LH}(\mathrm{mIU} / \mathrm{ml})$ & $8.25 \pm 4.80$ & $6.77 \pm 4.07$ & 0.081 \\
\hline
\end{tabular}

* - Mean difference significant at $\mathrm{p} \leq 0.05 ; \mathrm{n}$ - Number of subjects in the group; SD - Standard Deviation; FBS - Fasting Blood Sugar; HbA1c - Glycated Haemoglobin; FSH - Follicle Stimulating Hormone; LH - Luteinizing Hormone

Table 2: Biochemical parameters (Mean $\pm \mathrm{SD}$ ) in female diabetic and female control subjects

\begin{tabular}{|l|c|c|c|c|c|c|}
\hline & \multicolumn{2}{|c|}{ Group A $-<50$ Years (N=100) } & \multicolumn{3}{c|}{ Group B $-\geq 50$ Years (N=138) } \\
\hline Parameter & $\begin{array}{c}\text { Diabetic } \\
\mathbf{n = 6 0}\end{array}$ & $\begin{array}{c}\text { Control } \\
\mathbf{n = 4 0}\end{array}$ & $\boldsymbol{p}$ value & $\begin{array}{c}\text { Diabetic } \\
\mathbf{n = 8 8}\end{array}$ & $\begin{array}{c}\text { Control } \\
\mathbf{n = 5 0}\end{array}$ & $\boldsymbol{p}$ value \\
\hline $\begin{array}{l}\text { FBS } \\
(\mathrm{mmol} / \mathrm{l})\end{array}$ & $9.48 \pm 4.64$ & $4.69 \pm 0.44$ & $<0.001^{*}$ & $7.94 \pm 3.23$ & $4.62 \pm 0.42$ & $<0.001^{*}$ \\
\hline $\mathrm{HbA1c}(\%)$ & $7.16 \pm 1.02$ & $5.15 \pm 0.87$ & $<0.001^{*}$ & $7.61 \pm 1.25$ & $4.97 \pm 0.90$ & $<0.001^{*}$ \\
\hline $\begin{array}{l}\mathrm{FSH} \\
(\mathrm{mIU} / \mathrm{ml})\end{array}$ & $17.79 \pm 3.73$ & $19.95 \pm 4.16$ & $0.008^{*}$ & $73.58 \pm 23.25$ & $82.58 \pm 19.97$ & $0.018^{*}$ \\
\hline $\begin{array}{l}\mathrm{LH} \\
\mathrm{mIU} / \mathrm{ml})\end{array}$ & $28.66 \pm 3.60$ & $28.98 \pm 4.25$ & 0.686 & $44.44 \pm 24.62$ & $38.59 \pm 11.40$ & 0.059 \\
\hline
\end{tabular}


* - Mean difference significant at $\mathrm{p} \leq 0.05 ; \mathrm{n}$ - Number of subjects in the group; SD - Standard Deviation; FBS - Fasting Blood Sugar; HbA1c - Glycated Haemoglobin; FSH - Follicle Stimulating Hormone; LH - Luteinizing Hormone

The correlation results (Table 4 ) in the male diabetic population and the female diabetic group A population $(<50$ years) showed that HbA1c had no significant relationship $(\mathrm{p}>0.05)$ with FSH and LH. The analysis for the Female diabetic group B population ( $\geq 50$ years), however disclosed that HbA1c gave significant positive correlation with both FSH $(r=0.261, p=0.014)$ and $\mathrm{LH}(\mathrm{r}=0.338$, $\mathrm{p}<0.001)$ in the group B diabetics.

\section{Discussion}

Although diabetes mellitus is associated with many complications, its control results in reduction of not only morbidity and mortality, but also economic burden of the disease (Azab, 2001).

The results of this study showed that fasting blood sugar and the glycated haemoglobin level were significantly higher in type 2 diabetic patients and thus confirms their hyperglycaemic state. HbAlc value $\leq 7.0 \%$ is recommended to be appropriate for reducing the risk for cardiovascular complications (ADA, 2003). It has been estimated that reducing the HbA1c level by $0.2 \%$ could lower the mortality by $10 \%$ (Khaw, 2001).

Table 3: Biochemical parameters (Mean \pm SD) within glycaemic control status in diabetic subjects

\begin{tabular}{|c|c|c|c|c|c|c|}
\hline & \multicolumn{2}{|c|}{ Male } & \multicolumn{2}{|c|}{ Female Group A } & \multicolumn{2}{|c|}{ Female Group B } \\
\hline & \multicolumn{2}{|c|}{$\overline{(\mathrm{n}=92)}$} & \multicolumn{2}{|c|}{$(n=60)$} & \multicolumn{2}{|c|}{$(n=88)$} \\
\hline Par: & $\mathbf{r}$ & $p$ value & $\mathbf{r}$ & $p$ va & $\mathbf{r}$ & $p \mathrm{va}$ \\
\hline $\mathrm{HbA}$ & -0.058 & & -0.08 & 0.503 & 0.261 & \\
\hline HbA1c \& LH & 0.018 & 0.865 & 0.198 & 0.129 & 0.338 & $0.001 * *$ \\
\hline
\end{tabular}

* - Mean difference significant at $\mathrm{P} \leq 0.05 ; \mathrm{n}$ - Number of subjects in the group; SD - Standard Deviation; FBS - Fasting Blood Sugar; HbA1c - Glycated Haemoglobin; FSH - Follicle Stimulating Hormone; LH - Luteinizing Hormone Good (HbA1c < 7\%), Fair (HbA1c 7 to $8 \%$ ) and Poor (HbA1c > 8\%)

$\mathrm{a}-\mathrm{p}<0.05$ compared with Good glycaemic status

$b-p<0.05$ compared with Fair glycaemic status

Table 4: Relationship between HbA1c and gonadotrophins (FSH \& LH) in diabetic subjects

\begin{tabular}{|l|c|c|c|c|c|c|}
\hline \multirow{2}{*}{} & \multicolumn{2}{|c|}{ Male } & \multicolumn{2}{c|}{ Female Group A } & \multicolumn{2}{c|}{ Female Group B } \\
\cline { 2 - 8 } & \multicolumn{2}{|c|}{$(\mathbf{n = 9 2})$} & \multicolumn{2}{c|}{$(\mathbf{n = 6 0})$} & \multicolumn{2}{c|}{$(\mathbf{n}=88)$} \\
\hline Parameter & $\mathbf{r}$ & $\boldsymbol{p}$ value & $\mathbf{r}$ & $\boldsymbol{p}$ value & $\mathbf{r}$ & $\boldsymbol{p}$ value \\
\hline HbA1c \& FSH & -0.058 & 0.584 & -0.088 & 0.503 & 0.261 & $0.014^{*}$ \\
\hline HbA1c \& LH & 0.018 & 0.865 & 0.198 & 0.129 & 0.338 & $0.001 * *$ \\
\hline
\end{tabular}

$\mathrm{r}$ - Pearson Correlation Co-efficient, *Correlation significant at $\mathrm{p}<0.05$, ** Correlation significant at $\mathrm{p}<0.01 ; \mathrm{n}-$ Number of subjects in the group; HbA1c - Glycated Haemoglobin; FSH - Follicle Stimulating Hormone; LH - Luteinizing Hormone 
This study showed higher levels of FSH in the female diabetic groups when compared with their respective control groups. Conversely, the male diabetics had significantly lower FSH level with respect to the control. The glycaemic control evaluation gave significant results, only in the female populations. The group $\mathrm{B}$ diabetic females $(\geq 50$ years) demonstrated significant positive correlation of HbA1c with both FSH and LH.

Cakir et al., (1996), in a study carried out in male (40-78 years), premenopausal (22-50 years) and postmenopausal (52-70 years) female diabetics reported closely related findings. The mean levels of FSH and LH, together with prolactin, free testosterone and oestradiol, were not significantly different from the levels of their respective

controls. However, the premenopausal female diabetics had significantly higher mean FSH level compared to the control's level. They therefore, suggested that sexual dysfunction in diabetic patients is not related to hormonal insufficiency but may be the result of psychological, neurological and vascular involvement of the disorder. Ando et al., (1984) in their study also reported normal FSH and LH levels in male diabetics.

The pituitary gonadotrophic hormones finding of this study is however not in absolute agreement with some previous studies. Ali et al., (1993) and Natah et al., (2013) reported significant higher FSH and LH levels in diabetics than in control. Saudeep et al., (2004) has shown that both free and total testosterone levels, together with their levels of pituitary hormones (FSH and LH) are lower in men with type 2 diabetes than in non-diabetic men. Dhindsa et al., (2004) in their work showed that among diabetics with hypogonadism, LH and FSH levels were significantly lower in comparison with patients with normal free testosterone levels. The study carried out by Onah et al., (2013) in Nnewi, Nigeria, showed increased FSH, but no significant change in the level of LH in male diabetics when compared with control subjects.

The effects of diabetes on female sexuality are not so clear. One or more sexual dysfunctions have been reported in diabetic women: decreased libido, slow arousal, inadequate lubrication, anorgasmia or dyspareunia (Cakir et al., 1996). Kadhim and Ahmed (2015) in their study on female diabetics observed that FSH and LH, together with HbA1c were higher in the diabetic women (3048 years) compared with control individuals. In addition, Natah et al. (2013) reported that the levels of FSH and LH were significantly higher in female diabetes group than control. On the other hand, the study by Natah (2014), though not precisely in diabetics, but in Pre- and Postmenopausal metabolic syndrome women revealed that FSH and LH showed no significant differences between the metabolic groups and their age-matched controls. The effect of diabetes on female gonadotrophic and sex hormones and on sexual responses is conflicting, necessitating further advanced researches.

In this study, HbA1c gave positive correlation with FSH and LH in the group B diabetic females ( $\geq 50$ years). This could be due to the higher levels observed in patients with poor glycaemic status. This suggests that there is a direct relationship between HbA1c and the gonadotrophic hormones. As glycaemic control is compromised, these hormones tend to increase.

Nevertheless, in this study, it was observed that the increased or decreased levels of FSH and LH observed in the diabetic subjects in comparison with the control subjects were not above or below 
the acceptable levels, respectively. This observation was also seen in the works of other investigators (Saudeep et al., 2004; Natah et al. 2013, Onah et al., 2013).

It is also important to recognise the fact that the study populations are usually under therapeutic management. This possibly helps to keep the hormones normal, except for patients who have other disorders as reported by Cakir et al., (1996).

The diabetic subjects in this study were on metformin monotherapy. Metformin is an oral biguanide that reduces gastrointestinal glucose absorption and improves sensitivity to the action of insulin due to its inhibitory action on hepatic gluconeogenesis, secondarily, by augmenting glucose uptake in the peripheral tissues, mostly muscle (Hundal et al., 2000, Kirpichnikov et al., 2002). It is not known to affect gonadotrophin production or secretion.

Núñez Miguel et al., 2017 reported that the areas on the surfaces of glycoprotein hormones that are known to interact with their receptors are not glycosylated and two areas free from glycosylation, not involved in currently known interactions, have been identified. Furthermore, experimental evidence suggests that the non-glycosylated areas identified on the hormones and receptors are likely to be involved in forming intra- or inter-molecular interactions. In addition, other reports gave details on the effects of partial or complete deglycosylation on action of these hormones (Smith et al., 1990; Ulloa-Aguirre et al., 1995). Arey (2012) stated that the degree of glycosylation added to these hormones varies depending upon the physiological state and therefore, they are found in the plasma as a series of isoforms that vary in glycosylation complexity.

It could therefore hold that hypogonadism that have been observed in previous studies in diabetic patients, might not necessarily be due to hyperglycaemia, insulin resistance or glycosylation of the glycoprotein hormones but as a result of other underlying disrupting factors. It can thus be inferred that effective diabetic control could help reduce the possibility of having altered pituitary gonadotrophins levels.

\section{Conclusion}

This study revealed relatively normal FSH and LH levels in diabetic subjects, with increasing trend in the levels across the different glycaemic status categories. It can be concluded that good glycaemic control of diabetes can exert better influences on pituitary gonadotrophins.

\section{References}

[1] Ali S.T., Shaikh R.N., Ashfaqsiddiqi N. (1993). Serum and urinary levels of pituitary-gonada hormones in insulin-dependent and non-insulin-dependent diabetic males with or without neuropathy. Archives of Andrology, 30:117-123.

[2] American Diabetes Association (ADA) (2003). Tests in glycemia in diabetes. Diabetes Care. 26: 106-108.

[3] Ando, S., Rubens R., Rottiers R. (1984). Androgen plasma levels in male diabetics. Journal of Endocrinology Investigation, 7:21-24.

[4] Arey B.J. (2012). The Role of Glycosylation in Receptor Signaling. In: Glycosylation IntechOpen; $12: 273-286$. 
[5] Azab A. S. (2001). Glycemic control among diabetic patients. Saudi Medical Journal 22(5): 407409.

[6] Cakir N., Ayvaz G., Arslan M. and Boztepe U. (1996). Plasma Gonadotropin, Sex hormones and prolactin levels in Diabetic patients. Gazi Medical Journal 7: 97-99.

[7] Chen M., Dou J. (2014). Diabetes and gonadal disorders. Journal of Translational Internal Medicine 2(3):119-123.

[8] Dandona P., Dhindsa S. (2011). Hypogonadotropic hypogonadism in type 2 diabetes and obesity Journal of Clinical Endocrinology and Metabolism 96(9):2643-2651

[9] Dandona P., Mohanty P., Ghanim H., Aljada A., Browne R., Hamouda W., Prahala A., Afzal A., Garg R. (2001). The suppressive effect of dietary restriction and weight loss in the obese on the generation of reactive oxygen species by leukocytes, lipid peroxidation, and protein carbonylation. Journal of Clinical Endocrinology and Metabolism 1:355-362.

[10] Dhindsa S., Prabhakar S., Sethi M., Bandyopadhyay A., Chaudhuri A., Dandona D. (2004). Frequent occurrence of hypogonadism in type 2 Diabetes. Journal of Clinical Endocrinoloy and Metabolism; 89(11):5462-5468.

[11] Ghanim H., Garg R., Aljada A., Mohanty P., Kumbkarni Y., Assian E., Hamouda W., Dandona P. (2001). Suppression of nuclear factor-kappaB and stimulation of inhibitor kappaB by troglitazone: evidence for an anti-inflammatory effect and a potential antiatherosclerotic effect in the obese. Journal of Clinical Endocrinoloy and Metabolism; 86(3):1306-1312.

[12] Harvey R.A. and Ferrier D.R. (2011). Lipid Metabolism; Diabetes Mellitus. In: Lippincott's Illustrated Reviews: Biochemistry (5th ed). Lippincott Williams \& Wilkins Philadelphia 173-244; 337-348

[13] Hundal R., Krssak M., Dufour S., Laurent D., Lebon V., Chandramouli V., Inzucchi S., Schumann W., Petersen K., Landau B., Shulman G. (2000). Mechanism by which metformin reduce blood glucose production in type 2 diabetes. Diabetes; 49(12): 2063-2069.

[14] Kadhim R.J. and Ahmed S.A. (2015). Study the Comparison of Gonadotropin Levels in Diabetes Mellitus Females. Journal of Al-Nahrain University. 18 (3):33-37.

[15] Khaw K.T., Wareham N., Luben R., Bingham S., Oakes S., Welch A., Day N. (2001). Glycated haemoglobin, diabetes, and mortality in men in Norfolk cohort of European Prospective Investigation of Cancer and Nutrition (EPIC-Norfolk). British Medical Journal; 322(7277):15-18.

[16] Kirpichnikov D, McFarlane SI \& Sowers JR (2002). Metformin: an update. Annals of Internal Medicine, 137: 25-33.

[17] Natah T.M., Wtwt M.A., Al-Saadi H.K., Al-Saadi A.H, Farhood H.F. (2013). Study the levels of adiponectin, FSH, LH and sex hormones in Type 2 diabetes (NIDDM). Journal of Biology, Agriculture and Healthcare 3:172-181.

[18] Natah T.M. (2014). Serum adiponectin levels in pre-postmenopausal metabolic syndrome women and the correlation with some physio-biochemical parameters. Australian Journal of Basic and Applied Sciences, 8(17): 360-366.

[19] Nathan D.M., Turgeon H., Regan S. (2007). Relationship between glycated haemoglobin levels and mean glucose levels over time. Diabetologia, 50:2239-2244.

[20] Núñez Miguel R., Sanders J., Furmaniak J., Rees Smith B. (2017). Glycosylation pattern analysis of glycoprotein hormones and their receptors. Journal of Molecular Endocrinology; 58 (1):25-41.

[21] Onah C.E, Meludu S.C, Dioka C.E, Onuegbu J.A, Amah U.K, Olisekodiaka M.J, Okwara J.E, Onah C.F and Ezeugwunne I.P. (2013). Pattern of male sex hormones in type 2 diabetic patients in Nnewi, South Eastern Nigeria. Journal of Dental and Medical Sciences. 10 (4):65-70

[22] Onung S. I., Young E. E., Ugwu T. E., Fasanmade O. A. (2017). Hypogonadism in Nigerian men with type 2 diabetes mellitus. International Journal of Diabetes in Developing Countries 37 (3): 254-261

[23] Popova E. A., Mironova R. S., Odjakova M. K. (2010) Non-Enzymatic Glycosylation and Deglycating Enzymes. Biotechnology \& Biotechnological Equipment; 24(3): 1928-1935 
[24] Saudeep D, Sathyavani P, Manak S, Arindam B, Ajay C, Paresh D. (2004). Frequent Occurrence of Hypogonadotropic Hypogonadism in Type 2 Diabetes. Clinical Endocrinology and Metabolism. 89: 5462-5468.

[25] Schmidt AM, Hori O, Brett J, Yan SD, Wautier JL, Stern D. (1994). Cellular receptors for advanced glycation end products: implications for induction of oxidant stress and cellular dysfunction in the pathogenesis of vascular lesions. Arterioscler Thromb.; 14:1521-1528.

[26] Smith P.L., Kaetzel D., Nilson J., Baenziger J.U. (1990). The sialylated oligosaccharides of recombinant bovine lutropin modulate hormone bioactivity. Journal of Biological Chemistry 265:874-881.

[27] Syed I. A. A. (2011). Glycated haemoglobin: past, present and future, are we ready for the change. Journal of Pakistan Medical Association; 61(4): 383-388.

[28] Ulloa-Aguirre A., Midgley A.R., Jr., Beitins I.Z., Padmanabhan V. (1995). Follicle-stimulating isohormones: characterization and physiological relevance. Endocrine Reviews 16:765-787.

[29] Younus H., Anwar S. (2016). Prevention of non-enzymatic glycosylation (glycation): Implication in the treatment of diabetic complication. International Journal of Health Sciences, Qassim University; 10(2): 261-277

*Corresponding author.

E-mail address: engeenan@gmail.com/madukaig@yahoo.com 